\title{
Electrical properties of epoxy composites based on carbon black
}

\author{
Artyom A. Shestakov ${ }^{1}$, Nikita I. Lapekin ${ }^{1}$, Andrey E. Brester ${ }^{1}$, Evgenii A. Maksimovskii ${ }^{2}$, \\ Arina $V$. Ukhina ${ }^{3}$, and Alexander $G$. Bannov ${ }^{11}$ \\ ${ }^{1}$ Novosibirsk State Technical University, Novosibirsk, 630073, Russia \\ ${ }^{2}$ Nikolaev Institute of Inorganic Chemistry SB RAS, Novosibirsk, 63009, Russia \\ ${ }^{3}$ Institute of Solid State Chemistry and Mechanochemistry SB RAS, 630090, Russian Federation
}

\begin{abstract}
In this work, $\mathrm{AC}$ electrical properties of epoxy composites based on carbon black (CB) were determined depending on the loading of filler. The measurements were carried out within a frequency range $20 \mathrm{~Hz}$ $-1 \mathrm{MHz}$. The loading of carbon black was $0-5 \mathrm{wt} . \%$ in composites. The conductivity increased when increasing the content of carbon black and the maximum values were observed at $5 \mathrm{wt} \% \mathrm{CB}$. The maximum value of permittivity was at $0.75 \mathrm{wt} . \% \mathrm{CB}$ and it can be considered as percolation threshold.
\end{abstract}

\section{Introduction}

Improvement of properties of epoxy composites can be achieved through controlling the parameters of preparation of composite, curing, and by means of use of various fillers. There is a wide variety of fillers for epoxy resins. The selected filler makes it possible to determine the chemical resistance, water uptake, hardness, electrical conductivity, permittivity and other characteristics of composites [1]. Most of the carbon fillers are used to enhance the electrical properties. The carbon material creates a three-dimensional network of filler particles in the polymer matrix. This behavior of transport properties of such a system can be described by means of percolation theory. When the percolation threshold is reached, a sharp drop in the transport properties is observed by several orders of magnitude [2,3]. The percolation is only applicable for a system of insulating material (dielectric) and conductive material (conductor) when an insulator-conductor transition is observed. Percolation threshold depends on the aspect ratio of filler [4,5]. There is a large number of works where carbon nanomaterials, e.g. multi-walled carbon nanotubes (MWCNTs) are used as filler [1-3,6,7]. The percolation threshold when using MWCNTs ranges from $0.05 \mathrm{wt} \%$ to $10 \mathrm{wt} . \%$ and depends on the properties of filler.

It is possible to achieve a lower percolation threshold when using MWCNTs as filler, but at the same time MWCNTs are several orders of magnitude more expensive than carbon black (CB), the latter is the most frequently used conventional filler. Studies show that, at a frequency of $100 \mathrm{~Hz}$, the conductivity of the epoxy oligomer is $3 \cdot 10^{-9} \mathrm{~S} / \mathrm{cm}[8]$ and $10^{-10}$

\footnotetext{
${ }^{1}$ Bannov.alexander@gmail.com (A.G. Bannov)
} 
$\mathrm{S} / \mathrm{cm}$ [9]. With the introduction of a small amount of $\mathrm{CB}(1 \% \mathrm{wt} . \%)$ there is a slight increase in the conductivity $\left(2.16 \cdot 10^{-9} \mathrm{~S} / \mathrm{cm}\right)$. Further increase in the concentration of $\mathrm{CB}$ (up to 6 wt.\%) also leads to a slight increase in the conductivity $\left(3.6 \cdot 10^{-9} \mathrm{~S} / \mathrm{cm}\right.$ ). Conductivity increases by several orders of magnitude when increasing the concentration above 17.29 wt.\% [10]. The electrical conductivity of epoxy/CB composite increasing with concentration of filler. At the same time, the obtained data do not show a pronounced conductivity plateau, which allows us to determine the electrical conductivity at direct current $\left(\sigma_{\mathrm{DC}}\right)$. This is caused by the Maxwell-Wagner-Sillars interfacial polarization effect, since charge carriers are trapped at the interfaces of heterogeneous systems, this leads to charge separation, and the permittivity values fall to the values of pure epoxy resin [11]. At low frequencies, the charge carriers travel a long distance inside the composite to change the direction of the electric field. In this case, the average distance carried by the charge carrier at frequencies less than the critical frequency is greater than the correlation length (the size of the largest cluster). At high frequencies, the electrical conductivity is realized by a charge carrier jump between localized states, which results in an almost linear increase in the dependence $\sigma(\omega)[12]$.

In this work, carbon black was used as a filler for epoxy composites. AC electrical properties of epoxy/CB composite were investigated.

\section{Experimental}

DER-331 bisphenol A epoxy resin was used as an epoxy composite (DOW Chemical, Germany). Carbon black (Alfa AesarTM) was used as a filler. The main characteristics are shown in Table 1.

Table 1. Characteristics of carbon black.

\begin{tabular}{|c|c|}
\hline Color & black \\
\hline Density, $\mathrm{g} / \mathrm{cm}^{3}$ at $20{ }^{\circ} \mathrm{C}$ & $1.8-2.1$ \\
\hline Bulk density, $\mathrm{g} / \mathrm{L}$ & $80-120$ \\
\hline Surface area, $\mathrm{m}^{2} / \mathrm{g}$ & 75 \\
\hline
\end{tabular}

The CB concentration in the epoxy composite was ranged from 0 to $5 \mathrm{wt} . \%$. Stirring of epoxy-CB mixture was carried out using a device with a mechanical stirrer IKA Eurostar Power Control-Visc P7 for the treatment of highly viscous media. The parameters of this device are shown in Table 2.

Table 2. Parameters of the device with an overhead stirrer.

\begin{tabular}{|c|c|}
\hline Type of agitator & Anchor enameled \\
\hline Number of blades & 2 \\
\hline Stirrer interior type & single cylinder \\
\hline h/d ratio & $20 / 15$ \\
\hline Drag coefficient $\mathrm{z}$ & 0.65 \\
\hline Torque range, rpm & $8-290$ \\
\hline $\begin{array}{c}\text { Maximum viscosity used for mixing, } \\
\mathrm{mPa} \cdot \mathrm{s}\end{array}$ & 150000 \\
\hline
\end{tabular}

After mixing epoxy resin with $\mathrm{CB}$, the hardener PEPA (polyethylene polyamine) was added. The ratio of epoxy to hardener was $6: 1$. The resulting suspension was poured into silicone molds with a diameter of $6 \mathrm{~mm}$, and left to cure under vacuum for $24 \mathrm{~h}$. After 
curing, the edges of the cylindrical tablets were polished so that they were plane-parallel. A silver-based conductive glue (Connector, Russia) was applied to each face and a layer of aluminum foil was glued. The obtained samples were placed in a cell (Fig. 1). A copper substrate and copper clamps were used as electrodes. The heater was located under the bottom electrode. The regulation was carried out using the PID-controller "Termodat13K6" (LLC NPP "Control Systems", Russia).
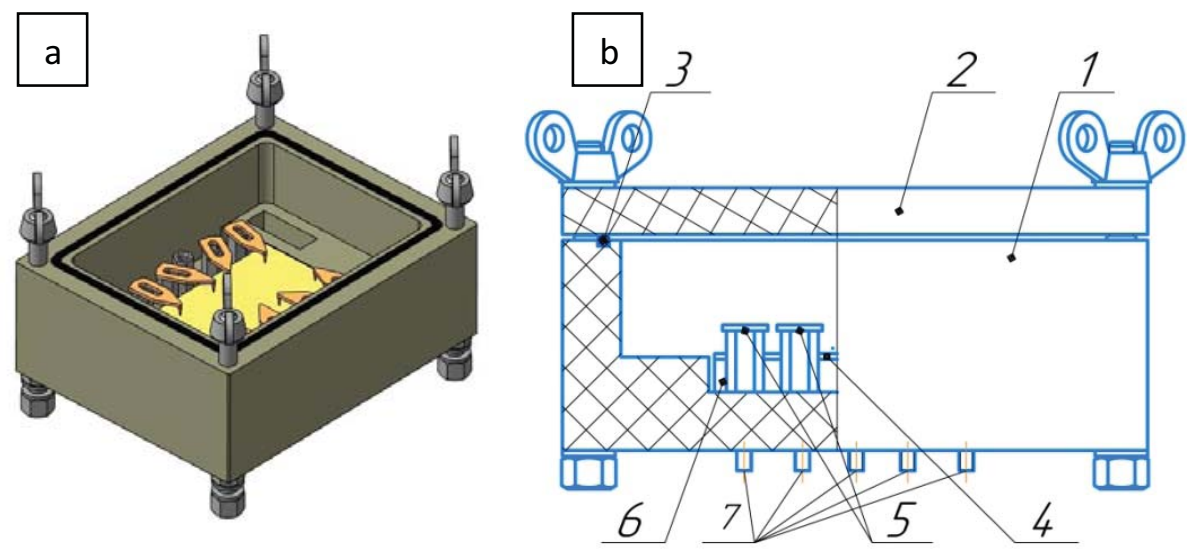

Fig. 1. Cell for the LCR meter: (a) - 3D model of cell; (b) - 2D model of cell: (1) frame; (2) cover; (3) strimp; $(4,5)$ electrodes; $(6)$ holder for meter; $(7)$ heater.

The electrical properties of composites were measured using an E7-25 LCR meter (RLC) (MNIPI, Belarus). The measurements were carried out at in a frequency range $1 \mathrm{~Hz}-1 \mathrm{MHz}$. To calculate the electrical properties, the following formulae were used. The permittivity was calculated using the formula (1).

Where $\mathrm{C}$ - capacitance, $\mathrm{F}$;

$$
\varepsilon=\frac{\mathrm{c} \cdot \mathrm{H}}{\varepsilon_{0} \cdot \mathrm{S}}
$$

$\mathrm{H}$ - sample height, $\mathrm{m}$;

$\varepsilon_{\circ}-$ permittivity of vacuum;

$\mathrm{S}-$ area of sample, $\mathrm{m}^{2}$.

Conductivity of sample was calculated according to formula (2).

$$
\sigma=\frac{G \cdot \mathbf{R}}{S}
$$

Where $\mathrm{G}$ - conductance, $\mathrm{S} \cdot \mathrm{m}$;

$\mathrm{R}$ - thickness of sample, $\mathrm{m}$.

\section{Results and Discussion}

It follows from Figure 2 that the conductivity varies in the range from $3 \cdot 10^{-9} \mathrm{~S} / \mathrm{m}$ to $6 \cdot 10^{-5}$ $\mathrm{S} / \mathrm{m}$. The values of conductivity below $10 \mathrm{kHz}$ are not shown since the high resistance of samples induces the errors of measurements (at conductivity below $10^{-9} \mathrm{~S} / \mathrm{m}$ ). At relatively low concentrations of carbon materials in the system (up to $2.5 \mathrm{wt} . \% \mathrm{CB}$ ), the dependence of the increase in the specific conductivity on frequency is better seen. At higher loadings ( 2.5 wt.\% CB and higher), the curves have a more linear relationship. 


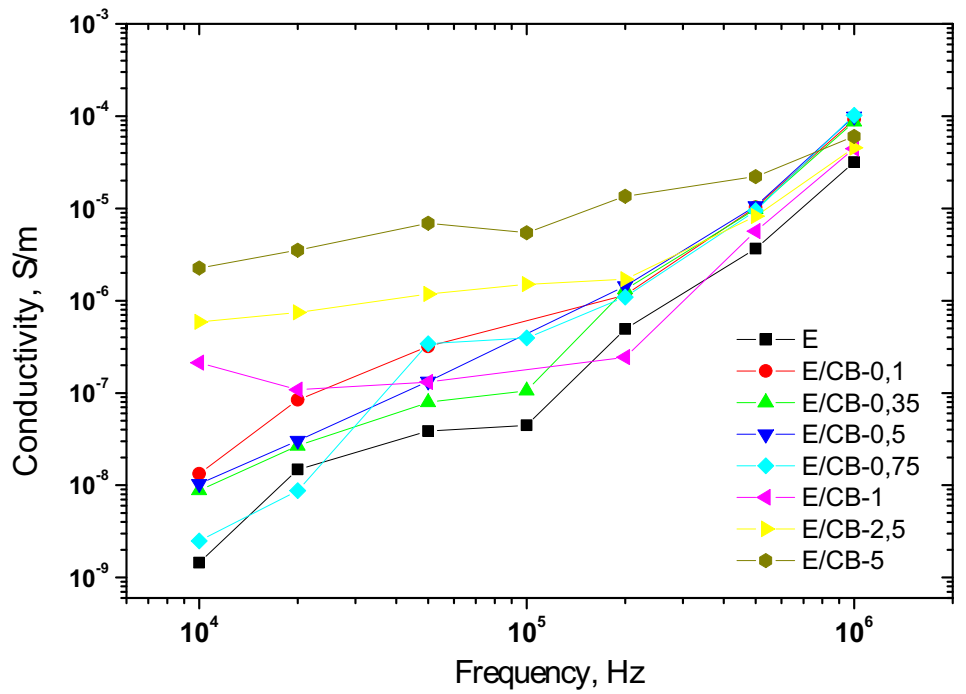

Fig. 2. Dependence of the conductivity on the frequency for epoxy/CB composites.

As shown in Fig. 3, the permittivity varies in the range from 7 to 1040 . The lowest value was shown by pure epoxy, while addition of carbon black induces growth both low frequency and $\varepsilon_{\infty}$ values. The highest values of the permittivity were observed at low frequencies $(50-100 \mathrm{~Hz})$. This effect was also found for a variety of nanosized and conventional fillers, such as carbon nanofibers [13], MWCNTs [14], etc. The maximum values of the permittivity were observed at $0.75 \mathrm{wt} . \%$ That is most likely caused by the percolation effect, where the maximum value of the transport properties corresponds to the percolation threshold. It can be noted that the obtained composites had the electrical properties which can provide their application in the field of electrostatic discharge and electromagnetic shielding $[15,16]$.

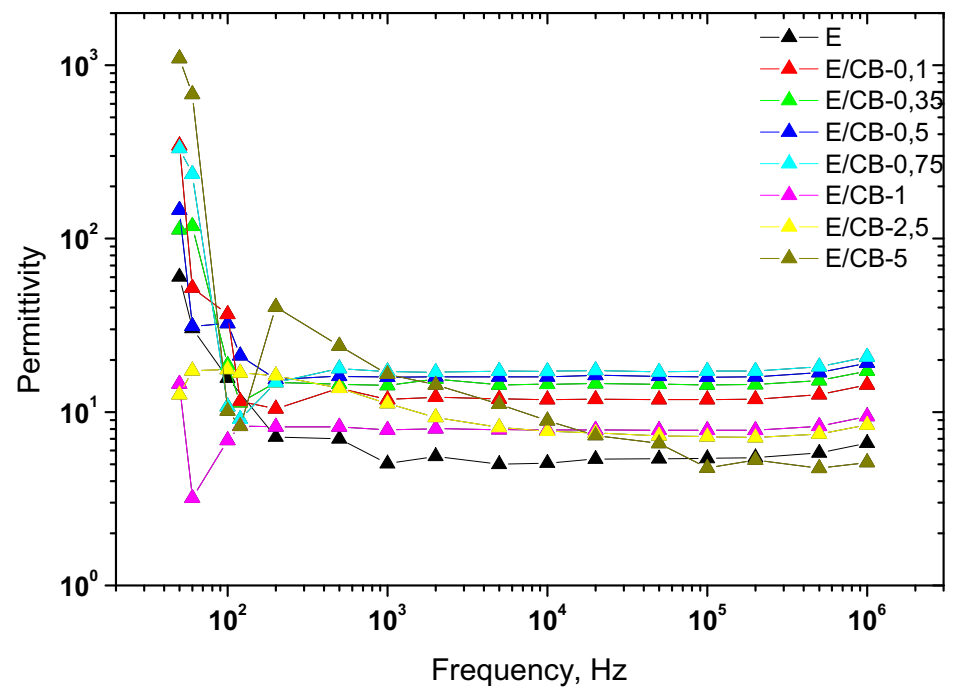

Fig. 3. Dependence of the permittivity on the frequency for epoxy/CB composites. 


\section{Conclusions}

In this work, the composites of epoxy oligomer DER-331 based on carbon black were produced. The $\mathrm{CB}$ content varied from 0 to $5 \mathrm{wt} \%$. The electrical properties of these systems were measured: permittivity and specific conductivity. The frequency range was 20 $\mathrm{Hz}-1 \mathrm{MHz}$. It was found that the conductivity increased when increasing the content of carbon black and the maximum values were observed at $5 \mathrm{wt} . \% \mathrm{CB}$. The maximum value of permittivity was at $0.75 \mathrm{wt} . \% \mathrm{CB}$ and it can be considered as percolation threshold.

The work was carried out within a scope of State task of Ministry of Science and Higher Education of Russia (project no. FSUN-2020-0008).

\section{References}

1. M. González, J. Pozuelo, J. Baselga, Chem. Rec. 18, 1000 (2018)

2. Z. Spitalsky, D. Tasis, K. Papagelis, C. Galiotis, Prog. Polym. Sci. 35, 357 (2010)

3. W. Bauhofer, J.Z. Kovacs, Compos. Sci. Technol. 69, 1486 (2009)

4. G.L. Yuan, N. Kuramoto, Polymer (Guildf). Elsevier BV. 44, 5501 (2003)

5. C. Singh, M. Shaffer, I. Kinloch, A. Windle, Physica B: Condens. Matter. 323, 329 (2002)

6. S. Gong, Z.H. Zhu, S.A. Meguid, Polymer 56, 498 (2015)

7. V.N. Popov, Mater. Sci. Eng. R: Rep. 43, 61 (2004)

8. P. Bertasius, D. Meisak, J. Macutkevic, P. Kuzhir, A. Selskis, E. Volnyanko, J. Banys, Polymers 11, 2044 (2019)

9. M. Blanco, G. Kortaberria, A. Jimeno, P. Arruti, A. Tercjak, I. Mondragon, Nanocomposites based on polymer matrix and carbon nanotubes as studied by dielectric spectroscopy (Transworld Research Network, Trivandrum, 2009)

10. A. Buketov, Adv. Mater. Sci. Eng. 20, 1 (2020)

11. Kremer F., Schönhals A. Broadband dielectric spectroscopy (Springer-Verlag, Berlin, 2003)

12. N.M. Barkoula, B. Alcock, N.O. Cabrera, T. Peijs, Polym. Polym. Compos. 16, 101 (2008)

13. A.G. Bannov, N.F. Uvarov, S.M. Shilovskaya, G.G. Kuvshinov, Nanotechnologies Russ. 7, 169 (2012)

14. Y.X. Zhou, P.X. Wu, Z.-Y. Cheng, J. Ingram, S. Jeelani, Express Polym. Lett. 2, 40 (2008)

15. J.K.W. Sandler, J.E. Kirk, I.A. Kinloch, M.S.P. Shaffer, A.H. Windle, Polymer 44 5893 (2003)

16. M. Arjmand, M. Mahmoodi, G.A. Gelves, S. Park, Carbon 49, 3430 (2011) 